УДК 623.48

DOI: https://doi.org/10.26642/ten-2021-2(88)-72-76

\author{
І.С. Аксютенко, аспірант \\ П.С. Аксютенко, студент \\ Національний технічний університет Украӥни \\ «Київський політехнічний інститут імені Ігоря Сікорського»
}

\title{
Технології та засоби організації системи технічного обслуговування
}

\author{
(Представлено: д.т.н., доц. Киричук Юрій Володимирович)
}

Зростання глобальної конкурениії призвело до помітних змін у способах роботи виробничих компаній. Ці зміни вплинули на технічне обслуговування $і$ зробили його роль ще більш важливою для успіху бізнесу. Щоб залишатися конкурентоспроможними, виробничі компаніі мають постійно підвищувати ефективність своїх виробничих процесів. Те, щчо технічне обслуговування стає все більш важливим для промислового сектору, очевидно з поточних обговорень національних програм індустріалізації. При цььому, незважаючи на зростаючий попит на надійне виробниче обладнання, деякі компанії-виробники займаються розробкою стратегічного обслуговування. Крім того, традииійних стратегій технічного обслуговування, таких як реактивне технічне обслуговування, більше недостатньо для задоволення промислових потреб, наприклад, як максимальне скорочення відмов і втоми виробничих систем.

У иій статті наведено аналіз стратегій технічного обслуговування. Їх огляд спрямований на те, щзоб вказати на важливість незапланованих простоїв, які можуть статися під час роботи обладнання на виробничому підприємстві. Для підтримки працездатного стану машини було розроблено різні стратегії технічного обслуговування, серед яких найбільш популярними $\epsilon$ реактивне технічне обслуговування, планово-профілактичне обслуговування і обслуговування на основі технічного стану. Метод прогнозованого стану більш ефективний для технічного обслуговування складних $і$ відповідальних машин, але планово-профілактичне обслуговування залишається найбільш поширеною програмою технічного обслуговування.

Ключові слова: технічний стан; відмови обладнання; технічне обслуговування; стратегї технічного обслуговування.

Актуальність теми. На сучасних промислових підприємствах виробничий процес став надзвичайно автоматизованим, що значно підвищило продуктивність і якість, знизивши рівень необхідних людських ресурсів. У той же час машини стають все більш складними, і сучасна машина може містити сотні компонентів. Несподіваний вихід з ладу одного компонента не тільки призводить до пошкодження самого пристрою, але також може вплинути на пов'язане 3 ним обладнання. Крім того, робота підприємства може бути перервана і призвести до значних економічних втрат. У деяких критичних промислових додатках збої системи можуть викликати надзвичайно серйозні наслідки, враховуючи вибухи, травми персоналу, викиди токсичних речовин тощо.

Щорічно промисловість витрачає на технічне обслуговування машин близько 40 \% від загального виробничого бюджету [1]. Причиною цих величезних витрат $є$ відсутність надійного та економічно ефективного методу прогнозування терміну корисного використання обладнання [2]. Тому дослідники та виробники намагаються вдосконалювати заходи технічного обслуговування, щоб забезпечити роботу підприємства, мінімізувати експлуатаційні витрати та продовжити термін експлуатації промислових машин, водночас забезпечуючи безпеку.

Аналіз останніх досліджень та публікацій, на які спираються автори. Важливість моніторингу стану та діагностики несправностей за останні десятиліття набула широкого визнання як в академічних, так і в промислових сферах. Щорічно проводиться декілька міжнародних конференцій на такі теми та тисячі публікацій у наукових виданнях, де вивчаються різні теми, враховуючи методи моніторингу [3], механічне моделювання дефектів [4-5], діагностику та прогноз несправностей [6-7]. Однак такі ефективні та передові методи рідко добре використовуються промисловістю. Найімовірніше промислові додатки частіше використовують традиційні методи, розроблені більше 20-30 років тому. Це свідчить про наявність розриву між науковими дослідженнями та промисловим застосуванням.

Метою статті $\epsilon$ аналіз стратегій технічного обслуговування, що використовуються для підтримки працездатного стану промислових машин.

Викладення основного матеріалу. Відмова обладнання визначається як «нездатність машини виконувати необхідні функції» [8]. Несправність може бути викликана безліччю причин, таких як недоліки в вихідній конструкції, неправильне виготовлення, невідповідне обслуговування та надмірні експлуатаційні вимоги [8]. Здебільшого відмова машини викликана поступовим зносом обладнання, який

(C) І.С. Аксютенко, П.С. Аксютенко, 2021 
збільшується під час роботи машини. Такий розвиток відмови може зайняти дні, тижні або місяці, $\mathrm{i}$ таким чином можна забезпечити попередження насування відмови на ранній стадії і своєчасно організувати операції 3 технічного обслуговування шляхом моніторингу стану працездатності машини [3].

На основі статистичного аналізу частоту відмов обладнання зазвичай можна описати як «криву відмов», що показано на рисунку 1 [8]. Ця крива підходить для окремої машини або великої кількості машин одного типу. Бачимо, що машина проходить три стадії: початковий знос, нормальний знос і кінцевий знос.

Початковий знос. Цей етап - початок терміну служби машини. На цьому етапі частота відмов має тенденцію бути відносно високою через помилки проєктування, виробничих дефектів, помилок збірки, проблем при установці і помилок введення в експлуатацію [8]. Після виявлення і виправлення цих збоїв частота збоїв швидко зменшується.

Нормальний знос. У період нормальної експлуатації відмови в роботі зазвичай мають випадковий характер. Їх поява багато в чому залежить від умовної роботи пристрою. Часті перевантаження, відхилення від режимів роботи, на які розрахована електромашина, збільшують ймовірність відмови. У цей період найважливіше значення має технічне обслуговування і своєчасне усунення відхилень від нормальних умов роботи.

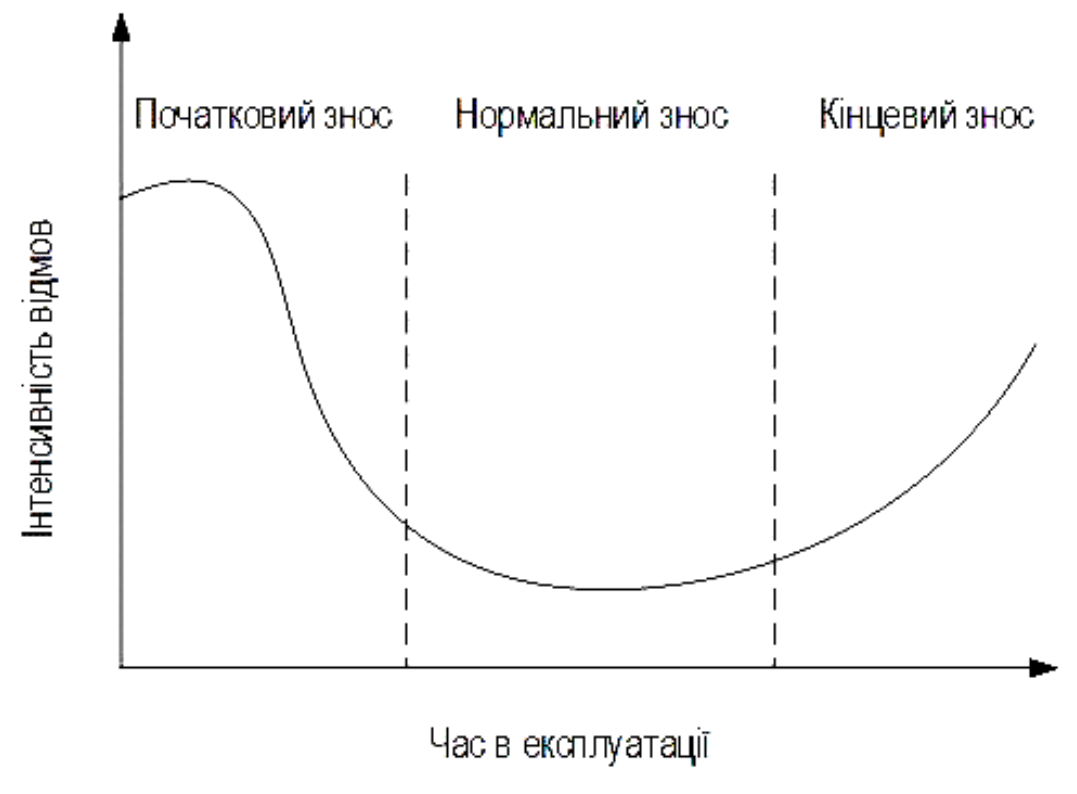

Рис. 1. Крива зношення обладнання [8]

Кінцевий знос. Коли машина поступово наближається до кінця розробленого терміну експлуатації, вона переходить у стадію зносу, під час якої рівень відмов має тенденцію до збільшення. У цей період несправності, як правило, спричинені втомою металу, механізмами зносу між рухомими частинами, корозією та застарілістю [3]. Варто враховувати, що нахил зношуваної деталі відрізняється в однієї машини та іншої, швидкість збільшення відмов значною мірою визначається конструкцією машини та ії експлуатаційною історією.

Для підтримки працездатного стану машини було розроблено різні стратегії технічного обслуговування. Серед них найбільш популярними є: реактивне технічне обслуговування, плановопрофілактичне обслуговування і обслуговування на основі технічного стану. Визначення, переваги та недоліки цих трьох стратегій описані нижче.

Реактивне технічне обслуговування. Технічне обслуговування, яке також називають технічним обслуговуванням після збою, проводиться лише тоді, коли машина повністю виходить 3 ладу, і не передбачено жодних заздалегідь визначених дій для запобігання відмові системи. Він передбачає ремонт або заміну несправного обладнання, щоб машина змогла виконувати необхідні функції після її виходу 3 ладу [9]. На рисунку 2 проілюстровано різні етапи реактивного технічного обслуговування. 


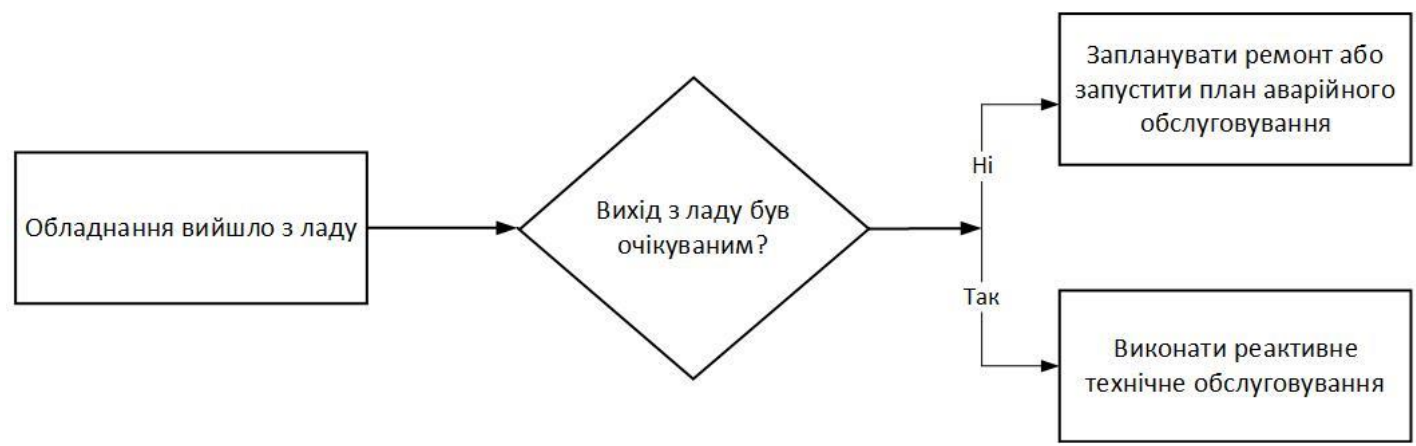

Рис. 2. Процес реактивного обслуговування [10]

Така стратегія використовується відносно недорогого допоміжного обладнання, що має резервні запчастини. У цьому випадку заміна механізму дешевше, ніж витрати на його ремонт і обслуговування. За відсутності резервування виробничий процес на час ремонту доводиться зупиняти. Часто під час експлуатації обладнання до виходу з ладу проводяться періодичні вимірювання вібраційного стану машини. Це дозволяє раціонально вибирати час ремонту і своєчасно забезпечити підготовку до ремонту.

Планово-профілактичне обслуговування (ППО). Ця стратегія також називається плановим обслуговуванням або технічним обслуговуванням за часом, що означає, що дії 3 технічного обслуговування готуються і виконуються задовго до виникнення несправності, поряд з розширенням знань про ймовірні несправності (рис. 3). Це виконується відповідно до заздалегідь визначеного плану, що означає, що технічне обслуговування виконується із заздалегідь визначеними інтервалами або відповідно за деякими заданими критеріями. Через обмеження знань про розробку правил відмов і відсутності наукових методів діагностики відмов, визначення інтервалів або критеріїв зазвичай грунтується на проєктних специфікаціях, попередньому досвіді і статистичних даних. Таким чином, важко запобігти нещасним випадкам, що викликані випадковими чинниками, і необхідність частого ремонту неминуча.

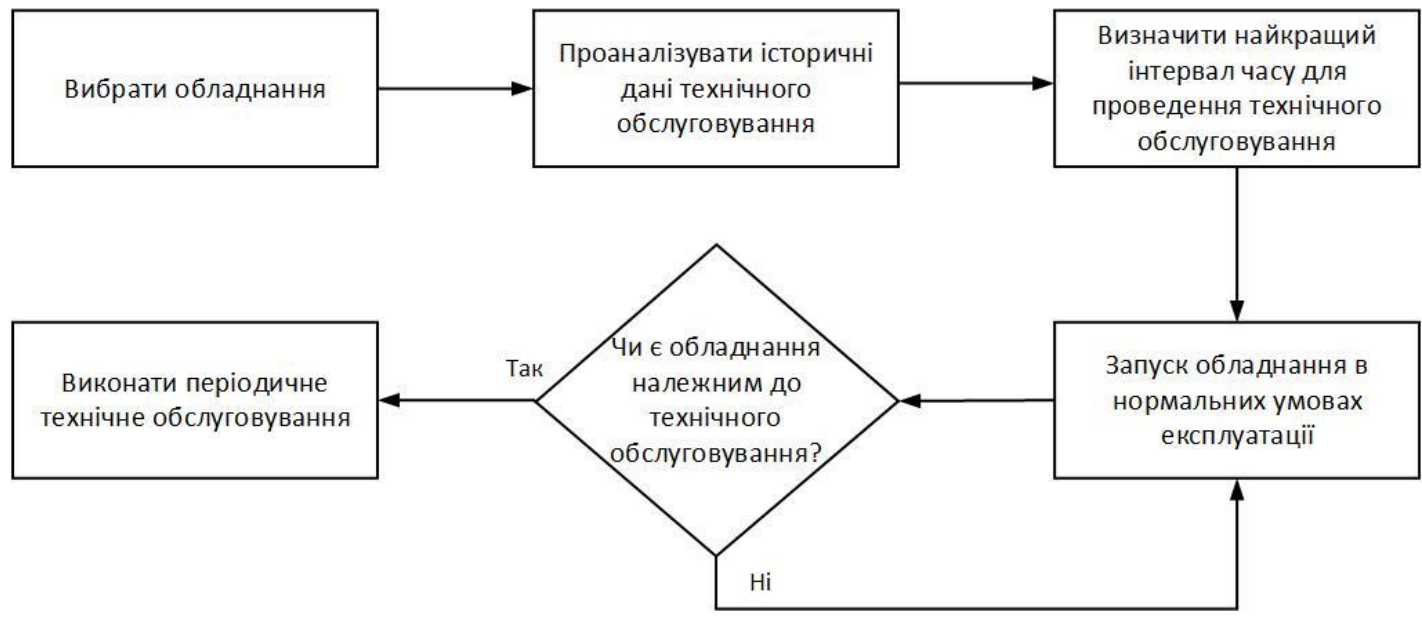

Рис. 3. Процес планово-профілактичного обслуговування [11]

Перевага профілактичного обслуговування полягає в тому, що, по-перше, технічне обслуговування можна спланувати так, щоб його можна було провести в зручний час; по-друге, менше аварій, особливо катастрофічних; по-третє, це більш ефективний спосіб контролю запасних частин і економії грошей. Однак недоцільно проводити технічне обслуговування через фіксований інтервал часу. 3 одного боку, якщо інтервал коротший, ніж його функціональний термін служби, виконання технічного обслуговування може призвести до значних витрат грошей i праці. 3 іншого боку, більш тривалі інтервали можуть бути занадто пізно для запобігання відмов чи для збереження необхідної функції. Крім того, непередбачені відмови все ще можуть відбуватися, а оцінка й оптимізація утомного ресурсу не відстежуються ефективно.

Прогнозоване технічне обслуговування. Відповідно до цієї стратегії, технічне обслуговування проводиться на основі знання стану машини, а не заздалегідь визначеного плану або графіка. Оптимальний час і зміст технічного обслуговування визначаються відповідно до даних оперативного виявлення і стану несправності машини, прогнозованого діагностичним блоком. При правильному 
проведенні програма технічного обслуговування на основі умов може успішно запобігти несподіваним катастрофічним збоям, підвищити надійність і доступність машини, скоротити час простою і підвищити ефективність роботи. Таким чином, ця стратегія технічного обслуговування дозволяє використовувати максимальний час роботи машини і мінімізувати витрати на технічне обслуговування. Ключ до технічного обслуговування на основі стану - це знання стану машини, яке можна отримати за допомогою різних методів моніторингу. Варто врахувати, що технічне обслуговування на основі стану вимагає додаткових інвестицій, оскільки необхідно встановити контрольно-вимірювальні прилади для моніторингу стану машини, а також можуть знадобитися фахівці для аналізу отриманих даних i пропозиції операцій з технічного обслуговування.

Порівняння трьох типів стратегій технічного обслуговування узагальнено в таблиці 1. Очевидно, що метод прогнозованого технічного обслуговування $є$ більш ефективним, ніж інші два методи, особливо для обслуговування складних та критичних машин. Але незважаючи на те, що цей підхід технічного обслуговування має величезний потенціал і $є$ стратегією, яка найбільш відповідає сьогоднішнім тенденціям цифровізації, планово-профілактичне обслуговування залишається найбільш поширеною програмою технічного обслуговування. Основними цілями всіх дій 3 технічного обслуговування $\epsilon$ продовження максимального терміну служби, дотримання стандартів безпеки та мінімізація витрат на технічне обслуговування [12].

Таблиия 1

Порівняння стратегій технічного обслуговування

\begin{tabular}{|l|l|l|}
\hline \multicolumn{1}{|c|}{ Стратегія } & \multicolumn{1}{|c|}{ Переваги } & \multicolumn{1}{|c|}{ Недоліки } \\
\hline $\begin{array}{l}\text { Реактивне технічне } \\
\text { обслуговування }\end{array}$ & Низька вартість обслуговування & $\begin{array}{l}\text { Може призвести до } \\
\text { величезних витрат на } \\
\text { ремонт (виробничі втрати) }\end{array}$ \\
\hline $\begin{array}{l}\text { Планово- } \\
\text { профілактичне } \\
\text { обслуговування }\end{array}$ & $\begin{array}{l}\text { Дозволяє зменшити кількість аварій } \\
\text { особливо катастрофічних } \\
\text { інтервали технічного } \\
\text { обслуговування. } \\
\text { Висока вартість } \\
\text { обслуговування }\end{array}$ \\
\hline $\begin{array}{l}\text { Прогнозоване технічне } \\
\text { обслуговування }\end{array}$ & $\begin{array}{l}\text { Здатний використовувати } \\
\text { максимальний час роботи машини. } \\
\text { Витрати на технічне обслуговування } \\
\text { можна значно скоротити, зменшивши } \\
\text { кількість непотрібних планово- } \\
\text { профілактичних робіт }\end{array}$ & $\begin{array}{l}\text { Додаткові інвестиції в } \\
\text { понрольно-вимірювальні } \\
\text { Для аналізу даних потрібні } \\
\text { фахівці }\end{array}$ \\
\hline
\end{tabular}

\section{Висновки:}

1. Відмова обладнання може бути викликана безліччю причин, таких як недоліки в вихідній конструкції, неправильне виготовлення, невідповідне обслуговування та надмірні експлуатаційні вимоги;

2. Для підтримки працездатного стану машини були розроблені різні стратегії технічного обслуговування, серед яких найбільш популярними є реактивне технічне обслуговування, плановопрофілактичне обслуговування і обслуговування на основі технічного стану;

3. Метод прогнозованого стану більш ефективний для технічного обслуговування складних i відповідальних машин, але планово-профілактичне обслуговування залишається найбільш поширеною програмою технічного обслуговування.

Список використаної літератури:

1. Eti M.C. Reducing the cost of preventive maintenance (PM) through adopting a proactive reliability-focused culture / M.C. Eti, S.O.T. Ogaji, S.D. Probert // Applied Energy. - 2006. - № 11. - P. 1235-1248. DOI: 10.1016/j.apenergy.2006.01.002.

2. Allgood G.O. It's Time for Sensors to Go Wireless; Part 2: Take a Good Technology and Make It an Economic Success / G.O. Allgood, W.W. Manges, S.F. Smith // The Journal of Applied Sensing Technology. - 1999. - № 5. P. 70-80.

3. Tavner P.J. Review of condition monitoring of rotating electrical machines / P.J. Tavner // IET Electric Power Applications. - 2008. - P. 215-247. DOI: 10.1049/iet-epa:20070280.

4. Numerical simulation and experimental study of a two-stage reciprocating compressor for condition monitoring / M.Elhaj, F.Gu, A.D. Ball et al. // Mechanical Systems and Signal Processing. - 2008. - Vol. 22, № 2. - P. 374-389. DOI: 10.1016/j.ymssp.2007.08.003. 
5. Bearing Fault Model for Induction Motor With Externally Induced Vibration / F.Immovilli, C.Bianchini, M.Cocconcelli et al. // IEEE Transactions on Industrial Electronics. - 2013. - Vol. 60, № 8 - P. 3408-3418. DOI: 10.1109/TIE.2012.2213566.

6. Urbanek J. Comparison of advanced signal-processing methods for roller bearing faults detection / J.Urbanek, T.Barszcz, T.Uhl // Metrology and Measurement Systems. - 2012. - P. 715-726. DOI: 10.2478/v10178-012-0063-2.

7. Bearing defect detection and diagnosis using a time encoded signal processing and pattern recognition method / S.Abdusslam, P.Raharjo, F.Gu, A.Ball // Journal of Physics Conference Series. - 2012. DOI: 10.1088/17426596/364/1/012036.

8. Clarence W. de Silva Vibration Monitoring, Testing, and Instrumentation / Clarence W. de Silva. - Boca Raton : CRC Press, 2007. -696 p.

9. Ahmad R. An overview of time-based and condition-based maintenance in industrial application / R.Ahmad, S.Kamaruddin // Computers \& Industrial Engineering. $\quad-\quad 2012 . \quad-\quad №$ 1. $\quad$ - P. 135-149. DOI: 10.1016/j.cie.2012.02.002.

10. Breakdown maintenance https://www.onupkeep.com/learning/maintenance-types/breakdown-maintenance.

11. What is Periodic Maintenance? [Електронний ресурс]. - Режим доступу : https://www.onupkeep.com/learning/maintenance-types/periodic-maintenance.

12. Kelly A. Maintenance Strategy / A.Kelly. $-1997 .-272$ p.

\section{References:}

1. Eti, M.C., Ogaji, S.O.T. and Probert, S.D. (2006), «Reducing the cost of preventive maintenance (PM) through adopting a proactive reliability-focused culture», Applied Energy, No. 11, pp. 1235-1248, doi: 10.1016/j.apenergy.2006.01.002.

2. Allgood, G.O., Manges, W.W. and Smith, S.F. (1999), «It's Time for Sensors to Go Wireless; Part 2: Take a Good Technology and Make It an Economic Success», The Journal of Applied Sensing Technology, No. 5, pp. 70-80.

3. Tavner, P.J. (2008), «Review of condition monitoring of rotating electrical machines», IET Electric Power Applications, pp. 215-247, doi: 10.1049/iet-epa:20070280.

4. Elhaj, M., Gu, F., Ball, A.D. et al. (2008), «Numerical simulation and experimental study of a two-stage reciprocating compressor for condition monitoring», Mechanical Systems and Signal Processing, Vol. 22, No. 2, pp. 374-389, doi: 10.1016/j.ymssp.2007.08.003.

5. Immovilli, F., Bianchini, C., Cocconcelli, M. et al. (2013), «Bearing Fault Model for Induction Motor With Externally Induced Vibration», IEEE Transactions on Industrial Electronics, Vol. 60, No. 8, pp. 3408-3418, doi: 10.1109/TIE.2012.2213566.

6. Urbanek, J., Barszcz, T. and Uhl, T. (2012), «Comparison of advanced signal-processing methods for roller bearing faults detection», Metrology and Measurement Systems, pp. 715-726, doi: 10.2478/v10178-012-0063-2.

7. Abdusslam, S., Raharjo, P., Gu, F. and Ball, A. (2012), «Bearing defect detection and diagnosis using a time encoded signal processing and pattern recognition method», Journal of Physics Conference Series, doi: 10.1088/1742-6596/364/1/012036.

8. Clarence, W. de Silva (2007), Vibration Monitoring, Testing, and Instrumentation, CRC Press, Boca Raton, 696 p.

9. Ahmad, R. and Kamaruddin, S. (2012), «An overview of time-based and condition-based maintenance in industrial application», Computers \& Industrial Engineering, No. 1, pp. 135-149, doi: 10.1016/j.cie.2012.02.002.

10. «Breakdown Maintenance», [Online], available at: https://www.onupkeep.com/learning/maintenancetypes/breakdown-maintenance

11. "What is Periodic Maintenance?», [Online], available at: https://www.onupkeep.com/learning/maintenancetypes/periodic-maintenance

12. Kelly, A. (1997), Maintenance Strategy, 272 p.

Аксютенко Ігор Сергійович - аспірант кафедри приладобудування Національного технічного університету України «Київський політехнічний інститут імені Ігоря Сікорського».

Наукові інтереси:

- прогнозоване технічне обслуговування;

- $\quad$ Інтернет речей.

Email: dustykid16@gmail.com.

Аксютенко Поліна Сергіївна - студентка четвертого курсу бакалаврату Національного технічного університету України «Київський політехнічний інститут імені Ігоря Сікорського».

Наукові інтереси:

- комп'ютерні технології;

- підземне будівництво.

Email: apollinaria007@gmail.com. 